\title{
Rancang Bangun Kombinasi Pompa Vakum Dengan Pompa Hidrolik Ram
}

\author{
Zakir Husin ${ }^{1}$, Maidi Saputra ${ }^{2}$ \\ ${ }^{1}$ Dosen Teknik Mesin Universitas Teuku Umar, ${ }^{2}$ Dosen Teknik Mesin Universitas Teuku \\ Umar \\ E-mail: zakirngn@yahoo.co.id
}

\begin{abstract}
Abstrak
Penelitian ini dilakukan dengan memanfaatkan kombinasi pompa hidram dengan pompa vakum yang ramah lingkungan tanpa menggunakan energi listrik dengan efesiensi yang tinggi. Desain Kombinasi Pompa Vakum dengan Pompa Hidrolik Ram menggunakan sofware Auto CAD dan sofware Sketchup. Dengan ukuran diameter pompa vakum $58 \mathrm{~cm}$, tinggi tabung pompa vakum 93 $\mathrm{cm}$, dengan kapasitas volume tabung pompa 220 liter, tinggi pompa hidram $85 \mathrm{~cm}$, dengan lebar pompa hidram yaitu $50 \mathrm{~cm}$. Hasil rata untuk tiga kali pengujian dalam waktu 10 menit volume air yang keluar rata-rata sebanyak 15 liter, dengan debit $1,5 \mathrm{l} / \mathrm{m}$, dan head losses nya $0,02 \mathrm{~m}$. tahap kedua dalam waktu 30 menit volume air yang keluar rata-rata dari tiga kali pengujian sebanyak 46,1 liter, dengan debit $1,53 \mathrm{l} / \mathrm{m}$, dan head losses nya $0,01 \mathrm{~m}$, dan tahap ketiga dalam waktu 60 menit volume air yang keluar sebanyak 92,6 liter, dengan debit 1,54 1/m, dan head losses nya 0,01 m. Dari hasil pengamatan maka metode ini mendapatkan kontinuitas yang baik dan dari nilai loses yang diperoleh maka efesiensi pompa tersebut cukup tinggi.
\end{abstract}

\section{Pendahuluan}

\subsection{Latar Belakang}

Air merupakan kebutuhan masyarakat, baik yang berasal dari sumber air permukaan maupun air tanah, pemanfaatan teknologi untuk mengalirkan air dari sumbernya ke area yang dibutuhkan perlu dikembangkan. (Nurul Fahmi, 2015). Salah satu teknologi yang mulai dikembangkan adalah pompa hydrolic ram atau lazim disebut pompa hidram. (Panjaitan, 2012)

Dalam perancangan pompa hidram agar mempunyai efisiensi sebaik mungkin di perlukan penelitian terhahap komponen-komponen utama pada pompa hidram. Dalam penelitian ini dilakukan penggunaan kombinasi pompa vakum dengan pompa hidram, sehingga terdapat pengaruh laju aliran fluida terhadap ketinggian pompa vakum dengan tekanan aliran fluida yang mempunyai efisiensi yang paling baik terhadap kapasitas dan kinerja dari pompa vakum dengan pompa hidram.

Dari berbagai penelitian terdahulu tentang pompa vakum dengan hidram, bahwa pompa vakum dengan pompa hidram telah lama dibuat dalam bentuk penelitian dan inovasi teknologi yang dibutuhkan oleh masyarakat perdesaan khususnya pada daerah perbukitan. Berbagai perancangan performasi pompa yang dilakukan agar mempunyai efisiensi sebaik mungkin. Merujuk dari beberapa penelitian terdahulu, berikut ini ada beberapa penelitian tentang pompa vakum dan pompa hidram.

Yaitu sebagai berikut: Penelitian yang di lakukan oleh Nurbet Wahyudi (2007). Penelitian tersebut dilakukan secara eksperimental terhadap pengaruh kapasitas drum (tabung) vakum dan tinggi pipa pengeluaran tehadap kontinuitas aliran pada pompa vakum. Penelitian yang di lakukan oleh Jimi Indriyan (2007). Penelitian tersebut dilakukan dengan metode eksperimental terhadap pengaruh perbedaan diameter pipa isap dan diameter pipa pengeluaran terhadap kontinuitas aliran pada pompa vakum. Hasil eksperimen menunjukkan pengaruh terhadap perbandingan diameter antara pipa isap dan 


\section{Jurnal Mekanova}

Vol 4. No. 2, April 2018

ISSN : 2502-0498

pipa keluar terhadap kontinuitas, dan kontinuitas terbaikdiperoleh pada saat diameter antara pipa masuk dan pipa keluar sama.

Penelitian yang di lakukan oleh Mietra Anggara. dkk, (2007). Penelitian tersebut untuk melihat pengaruh variasi panjang pipa masuk (drive pipe) dan beban katup buang (waste valve) terhadap efisiensi pompa hidram. Faktor panjang pipa masuk dan berat beban sangat berpengaruh terhadap debit pemompaan, debit buang, dan efisiensi pompa hidram.

Penelitian yang dilakukan oleh Kuswartomo, (2012). Penelitian ini dilakukan secara eksperimental untuk menganalisis karakteristik pompa hidram sebagai penghantar air terhadap variasi panjang drive pipe. Hasilnya menunjukkan bahwa semakin panjang drive pipe akan menghasilkan debit pemompaan yang semakin terbesar yang diikuti dengan ratio aliran yang semakin besar pula.

Pompa secara umum dapat diklasifikasikan menjadi 2 bagian

\section{Pompa Kerja Positif (Positive Displacement Pump)}

Pompa ini disebut juga dengan pompa aksi positif, dimana energi mekanik dari putaran poros pompa dirubah menjadi energi tekanan untuk memompakan fluida. Pada pompa jenis ini dihasilkan head yang tinggi tetapi kapasitas yang dihasilkan rendah (pompa putar/Rotary dan pompa torak/Reciprocating)

2. Pompa Sentrifugal (Dynamic Pump / Sentrifugal Pump)

Pompa jenis merupakan pompa yang bekerja dengan cara mempercepat aliran dan mempertinggi tekanan fluida dengan sudu impeler pada sebuah motor, fluida yang berkecepatan dan bertekanan terlempar keluar involut pompa.

\section{$1.2 \quad$ Jenis-Jenis Pompa}

Ada beberapa jenis-jenis pompa menurut prinsip dan cara kerjanya yaitu:

\section{Pompa Sentrifugal (Centrifugal Pump)}

Sifat dari hidrolik ini adalah memindahkan energi pada daun/kipas pompa dengan dasar pembelokan/pengubah aliran (fluid dynamics). Kapasitas yang di hasilkan oleh pompa sentrifugal adalah sebanding dengan putaran, sedangkan total head (tekanan) yang di hasilkan oleh pompa sentrifugal adalah sebanding dengan pangkat dua dari kecepatan putaran.

\section{Pompa Desak (Positive Displacement Pumps)}

Pompa jenis ini bekerja dengan cara perubahan periodik pada isi dari ruangan yang terpisah dari bagian hisap dan tekan yang dipisahkan oleh bagian dari pompa. Sedangkan kapasitas yang dihasilkan oleh pompa tekan adalah sebanding dengan kecepatan pergerakan atau kecepatan putaran, sedangkan total head (tekanan) yang dihasilkan oleh pompa ini tidak tergantung dari kecepatan pergerakan atau putaran.

\section{Jet pumps}

Pompa jenis ini bekerja untuk mendorong dan mengangkat cairan dari tempat yang sangat dalam. Perubahan tekanan dari nozzle yang disebabkan oleh aliran media yang digunakan untuk membawa cairan tersebut ke atas (prinsip ejector). Media yang digunakan dapat berupa cairan maupun gas. Pompa ini tidak mempunyai bagian yang bergerak dan konstruksinya sangat sederhana. Keefektifan dan efisiensi pompa ini sangat terbatas.

\section{Air lift pumps (mammoth pumps)}

Cara kerja pompa ini sangat tergantung pada aksi dari campuran antara cairan dan gas (two phase flow) 


\section{Hidraulic pumps}

Pompa ini menggunakan energi kinetik dari cairan yang dipompakan pada suatu kolom dan energi tersebut diberikan pukulan yang tiba-tiba menjadi energi yang berbentuk lain (energi tekan).

\section{Elevator Pump}

Sifat dari pompa ini mengangkat cairan ke tempat yang lebih tinggi dengan menggunakan roda timbah, archimedean screw dan peralatan sejenis.

\section{Electromagnetic Pumps}

Pompa ini bekerja langsung dari sebuah medan magnet padi media ferromagnetic yang dialirkan, oleh karena itu penggunaan dari pompa ini sangat terbatas pada cairan metal.

\subsection{Pompa Hidram}

Pompa hidram, berasal dari kata Hydraulic Ram Pump, yang berarti pompa air dengan tenaga hantaman air. Pomp hydraulic ram disingkat juaga dengan hidram berasal dari kata hidro $=$ air (cairan), dan ram = hantaman, pukulan atau tekanan, sehingga diterjemahkan menjadi tekanan air.

Pompa hidram adalah suatu alat yang digunakan untuk menaikkan air dari tempat rendah ke tempat yang lebih tinggi secara automatik dengan energi yang berasal dari air itu sendiri yaitu karena adanya tinggi air jatuh yang digunakan untuk menekan katup pada pompa hidram dan mengakibatkan water hammer. Tekanan air meningkat ketika air dihentikan secara tiba tiba karena ada perubahan momentum. Tekanan fluida yang tinggi digunakan untuk mengangkat sebagian fluida tersebut ke tempat yang lebih tinggi.

\subsection{Pompa Vakum}

Pada prinsipnya pompa ini bekerja secara mandiri dengan memanfaatkan tenaga hisap dari air yang keluar melalui lubang pengeluaran. Bila katup pengeluaran air (kran.2) dibuka, maka air dari drum akan keluar dan sejalan dengan ini air dari sumber/sumur ikut naik karena terhisap ke atas oleh air yang keluar. Oleh karena itu disebut dengan "Pompa Air Otomatis" seperti ditunjukkan pada gambar 1.

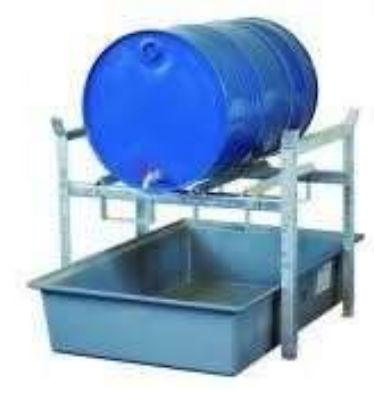

Gambar 1

\section{Metodologi}

2.1 Desain Kombinasi Pompa Vakum Dengan Pompa Hidrolik Ram 


\section{Jurnal Mekanova}

Vol 4. No. 2, April 2018

ISSN : 2502-0498

Desain Kombinasi Pompa Vakum dengan Pompa Hidrolik Ram menggunakan sofware Auto CAD dan sofware Sketchup. Dengan ukuran diameter pompa vakum $58 \mathrm{~cm}$, tinggi tabung pompa vakum $93 \mathrm{~cm}$, dengan kapasitas volume tabung pompa 220 liter, tinggi pompa hidram $85 \mathrm{~cm}$, dengan lebar pompa hidram yaitu $50 \mathrm{~cm}$.

\subsection{Perencanaan Kombinasi Pompa Vakum Dengan Pompa hidram}

Pada proses perancangan kombinasi pompa vakum dengan pompa hidram yaitu menggunakan sofware Auto CAD dan sofware sketchUp. Seperti gambar 2.
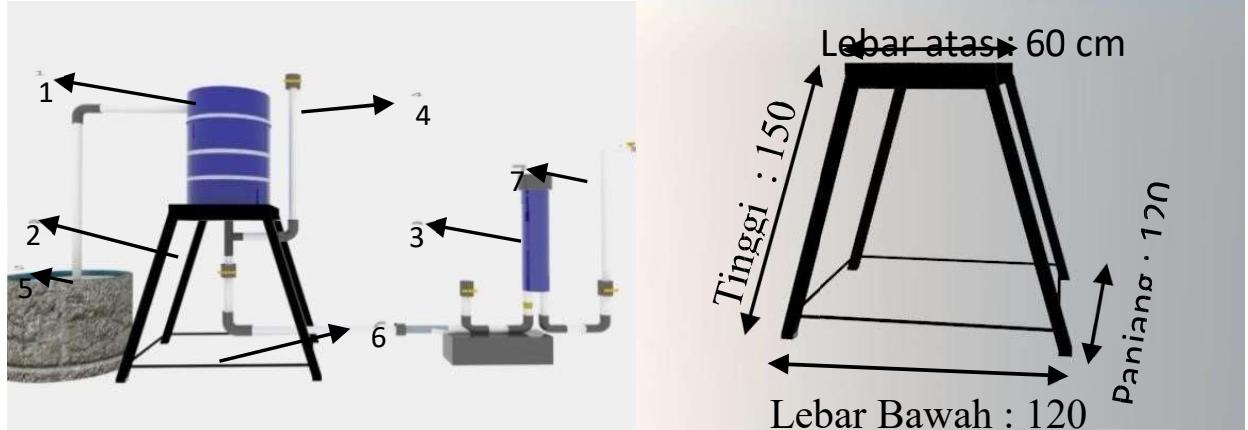

Gambar 2

Keterangan gambar :

1. Pompa vakum

2. Kerangka kedudukan pompa vakum

3. Pompa hidram

4. Pipa pengisian air ke pompa vakum

5. Pipa penghisap

6. Pipa air keluar dari pompa vakum ke pompa hidram

7. Pipa air keluar dari pompa hidram

Pada perencanaan pompa vakum, tabung pompa vakum menggunakan Drum dengan kapasitas volume air di dalamnya adalah 220 Liter. Maka tinggi dari drum pompa vakum adalah $93 \mathrm{~cm}$, dengan diameter drum adalah $58 \mathrm{~cm}$.

\subsection{Perencanaan Kerangka Kedudukan Pompa Vakum}

Pembuatan kerangka merupakan langkah awal dalam proses penelitian ini, yang mana kerangka benda kerja dipotong sesuai dengan gambar kerja yang telah direncanakan dengan menggunakan besi siku, plat strep dan pipa. Kemudian dilakukan proses pemotongan dengan menggunakan gerinda duduk dan gerinda tangan.

\subsection{Perencanaan Pompa Vakum}

Dalam proses pembuatan pompa vakum ini nantinya akan dilakukan menggunakan sebuah drum berkapasitas volume air yaitu 220 liter, sebelum dimulai proses pembuatan sebaiknya kita mendesain dulu sebuah gambar agar pada saat pembuatan akan lebih terarah. seperti gambar berikut:

\subsection{Perencanaan Pompa Hidram}

Dalam proses perencanaan pompa hidram nantinya akan dibuat menggunakan pipa, dengan tinggi pompa hidram $85 \mathrm{~cm}$ dan lebar pompa hidram $50 \mathrm{~cm}$. Seperti gambar 3 . 


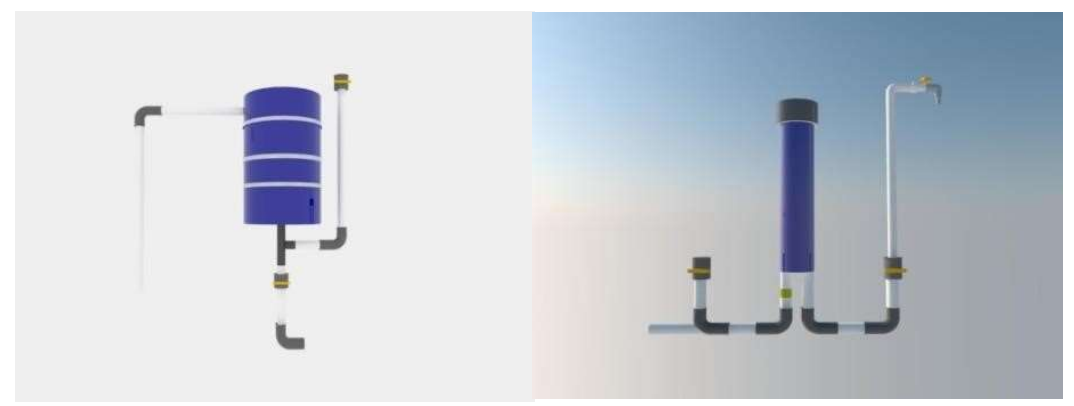

Gambar 3

\subsection{Metode Pengujian}

Pada proses pengambilan data ini dilakukan dalam tiga tahapan, dengan sembilan kali pengujian. Tahapan yang pertama dilakukan dalam waktu 10 Menit dengan tiga kali uji, Tahapan yang kedua dilakukan dalam waktu 30 Menit dengan tiga kali uji, dan tahapan yang ketiga dilakukan dalam waktu 60 Menit dengan tiga kali uji.

\section{PEMBAHASAN DAN HASIL}

Pembuatan kombinasi pompa vakum dengan pompa hidram memilik ukuran tinggi drum pompa vakum $93 \mathrm{~cm}$, lebar $58 \mathrm{~cm}$, panjang pipa penghisap 5 meter, panjang pipa pemasukan air ke pompa vakum $100 \mathrm{~cm}$, panjang pipa pengeluaran air dari pompa vakum ke pompa hidram 3 meter, ukuran kerangka pompa vakum memiliki tinggi $150 \mathrm{~cm}$, lebar $120 \mathrm{~cm}$, panjang $120 \mathrm{~cm}$ dan tinggi pompa hidram $85 \mathrm{~cm}$ dengan lebar pompa hidram 50 $\mathrm{cm}$. Dengan menggunakan Software Sketchup seperti pada gambar 4.1.

\subsection{Pembuatan Kombinasi Pompa Vakum dengan Pompa Hidram}

\subsubsection{Pembuatan tabung pompa vakum}

Pembuatan tabung pompa vakum yaitu dengan menggunakan drum dengan kapasitas air 220 liter, yang kemudian sisi atas drum dilubangi dengan 1 buah lubang, dan sisi bawah drum dilubangi dengan 1 buah lubang, lubang atas untuk pemasangan pipa penghisapan air, sedangkan lubang bawah untuk pemasangan pipa pengeluaran air yang akan menuju pompa hidram. Gambar 4 menunjukkan tabungpompa vakum tersebut.

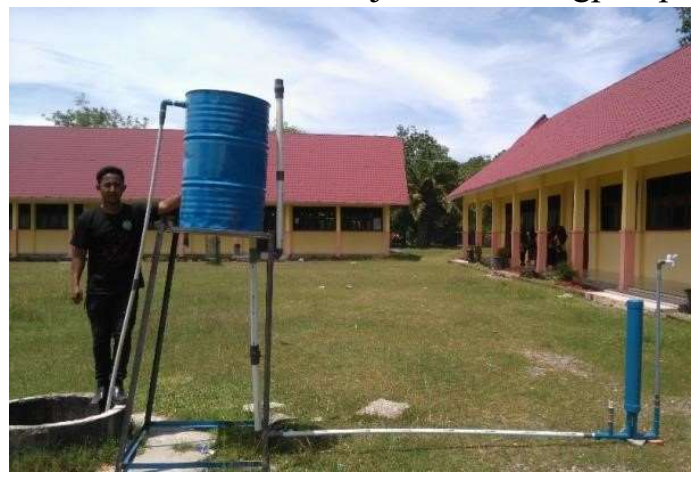

Gambar 4

\subsubsection{Hasil Perakitan Pompa Vakum Dengan Pompa Hidram}

Perakitan pompa vakum dengan pompa hidram merupakan proses menyatukan kedua pompa untuk menjadi suatu produk, sebagai mana kita tahu bahwa kedua pompa ini cuma memiliki satu keunggulannya masing-masing, pampa vakum cuma bisa untuk 


\section{Jurnal Mekanova \\ Vol 4. No. 2, April 2018 \\ ISSN : 2502-0498}

menghisap air dari dataran rendah ke permukaan saja, tetapi pompa vakum tidak dapat mengangkat air ke dataran yang lebih tinggi. Sedangkan pompa hidrolik ram biasanya digunakan di pinggiran sungai dengan memanfaatkan laju aliran air sungai, keunggulan pompa hidrolik ram cuma bisa untuk mengangkat air ke dataran yang lebih tinggi, tetapi pompa hidrolik ram tidak dapat menghisap air. Pada proses pengkombinasian ini kedua pompa dapat saling melengkapi dari kelemahan masing-masing pompa, pompa vakum dengan pompa hidrolik ram ini dapat menghasilkan sebuah keunggulan yaitu dapat menghisap air dari dataran rendah menuju ke dararan yang lebih tinggi tanpa harus memerlukan arus aliran sungai, selain itu pompa ini tidak memakai arus listrik.

\subsection{Tahapan Pengujian Kombinasi Pompa Vakum Dengan Pompa Hidram}

Pengujian dilakukan pada sebuah sumur di SMKN 1 Samatiga Kecamatan Samatiga Kabupaten Aceh Barat pada tanggal 31 agustus 2018.

Dengan langkah-langkah sebagai berikut:

1. Langkah pertama yaitu memeriksa seluruh bagian komponen katup, yaitu katup bawah saluran aliran ke pompa hidram ditutup supaya air yang diisi tidak dapat kuluar, sedangkan katup di atas dibuka supaya dapat mengisi air ke pompa vakum

2. Langkah kedua yaitu memasukkan air terlebih dahulu ke dalam pompa vakum, sehingga air terisi penuh di dalam pompa vakum

3. Langkah ketiga yaitu tutup katup pengisian air yang di atas jika pengisian air sudah penuh di dalam pompa vakum

4. Langkah keempat yaitu membuka katup saluran bawah yang akan mengalirkan air dari pompa vakum menuju ke pompa hidram.

Setelah melakukan langkah-langkah di atas, maka biarkan air di dalam pompa vakum tersebut mengalir ke pompa hidram dengan pengaruh ketinggian dari pompa vakum, air yang di pompa vakum mengalir ke pompa hidram dengan pengaruh daya dorongan akibat laju ketinggian, lalu menuju ke pompa hidram dan mendorong valve pertama untuk memompa air ke valve kedua yang ada di tabung pompa hidram, setelah terdorongnya velve ke dua maka air akan masuk ke dalam tabung pompa hidram dan valve kedua tersebut setelah terbuka dan memasukkan air ke dalam tabung maka valve kedua tersebut akan tertutup kembali, air yang telah masuk di dalam tabung pompa hidram tersebut kemudian akan dipompa melalui udara yang ada di tabung tersebut, setelah itu air yang di dalam tabung pompa hidram akan keluar dari tabung tersebut menuju valve ketiga dan mendorong valve ketiga, setelah valve ketiga terbuka maka air akan keluar melalui valve ketiga yang terbuka tersebut, setelah air dikeluarkan dari valve ketiga maka valve tersebut akan menutup kembali dan air yang dikeluarkan dari valve ketiga tersebut tidak dapat masuk kembali karena valve tersebut akan langsung tertutup. Sehingga air yang keluar dari valve yang ke tiga dikit demi sedikit akan penuh dan menaikkan air ke tempat yang lebih tinggi.

Dan air di dalam pompa vakum tidak akan berkurang, karena ketika air keluar dari pompa vakum dengan pengaruh ketinggian pompa vakum, maka secara otomatis pompa vakum akan menghisap air yang ada di kolam tersebut dengan sendirinya akibat adanya gaya penghisapan ketika air keluar lewat pompa hidram. Supaya penghisapan pompa tersebut tidak terjadinya kendala, dan penghisapan air yang lebih maksimal, maka ada beberapa syarat yang harus kita ketahui yaitu pompa vakum dan pipa penghisapan air dari kolam tidak ada yang bocor sedikitpun.

\subsection{Data Hasil Observasi Volume Aliran}

Data hasil observasi volume aliran yang diperoleh saat pengujian kombinasi pompa vakum dengan pompa hidrolik ram yaitu dengan cara menghitung volume air yang keluar dari pompa hidram. Pada proses pengambilan data ini dilakukan dalam tiga tahapan, dengan 


\section{Jurnal Mekanova}

Vol 4. No. 2, April 2018

ISSN : 2502-0498

sembilan kali pengujian. Tahapan yang pertama dilakukan dalam waktu 10 Menit dengan tiga kali uji, Tahapan yang kedua dilakukan dalam waktu 30 Menit dengan tiga kali uji, dan tahapan yang ketiga dilakukan dalam waktu 60 Menit dengan tiga kali uji. Berikut tabel yang menunjukkan data hasil pengujian volume air. Hasil observasi digambarkan dalam grafik pada gambar 5 .

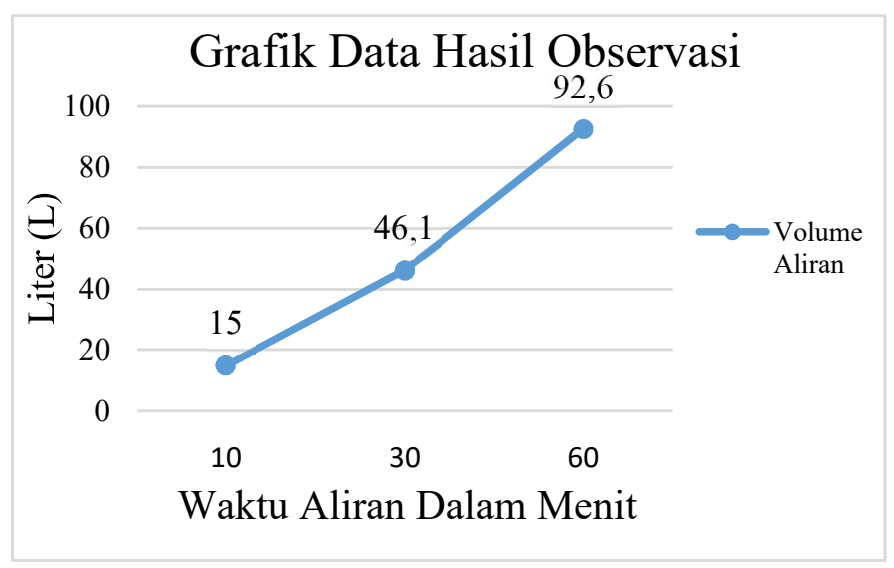

Gambar 5

Berdasarkan Gambar Data Hasil Observasi dapat dilihat bahwa hasil dari volume air yang keluar masih kurang stabil, hasil dari kurang stabilnya volume air yang keluar diakibatkan dari proses penghisapan dan hembusan air yang ada dalam pompa vakum.

\subsection{Hasil Analisis Perhitungan Debit}

Pada proses penelitian tahap pertama waktu yang di tentukan yaitu selama 10 menit, dalam 10 menit volume air rata-rata yang keluar dari tiga kali pengujian adalah sebanyak 15 liter.

Setelah diketahui volume air dengan jangka waktu aliran, maka langkah selanjutnya kita cari debit air yang keluar dari pompa hidram.

Diketahui : Volume (v) $=15$ liter

$$
\text { Waktu }(\mathrm{t})=10 \text { menit }
$$

Ditanya : Debit (Q) Jawab:

$\mathrm{Q}=\frac{v}{t}=\frac{15 \text { liter }}{10 \text { menit }}=1.5$ liter $/$ menit

Jadi debit air yang keluar dari pompa hidram adalah 1.5 liter/menit

Pada proses penelitian tahap kedua waktu yang di tentukan yaitu selama 30 menit, dalam 30 menit volume air rata-rata yang keluar dari tiga kali pengujian adalah sebanyak 46,1 liter.

Maka debit air yang dihasilkan yaitu:

Diketahui : Volume (v) $=46.1$ liter

Waktu $(\mathrm{t})=30$ menit Ditanya :

Debit (Q) Jawab: 


\section{Jurnal Mekanova}

Vol 4. No. 2, April 2018

ISSN : 2502-0498

$\mathrm{Q}=\frac{v}{t}=\frac{46.1 \text { liter }}{30 \text { menit }}=1.53$ liter $/$ menit

Jadi debit air yang keluar dari pompa hidram adalah 1.53 liter/menit

Pada proses penelitian tahap ketiga waktu yang di tentukan yaitu selama 60 menit, dalam 60 menit volume air rata-rata yang keluar dari tiga kali pengujian adalah sebanyak 92,6 liter.

Maka debit air yang dihasilkan yaitu:

Diketahui : Volume (v) $=92,6$ liter

Waktu $(\mathrm{t})=60$ menit Ditanya :

Debit (Q) Jawab :

$\mathrm{Q}=\frac{v}{t}=\frac{92,6 \text { liter }}{60 \text { menit }}=1.54$ liter $/$ menit

Jadi debit air yang keluar dari pompa hidram adalah 1.54 liter/menit.

Untuk lebih jelas berikut kita lihat grafik data hasil analisis perhitungan debit yang didapatkan saat pengujian yaitu pada gambar 6 .

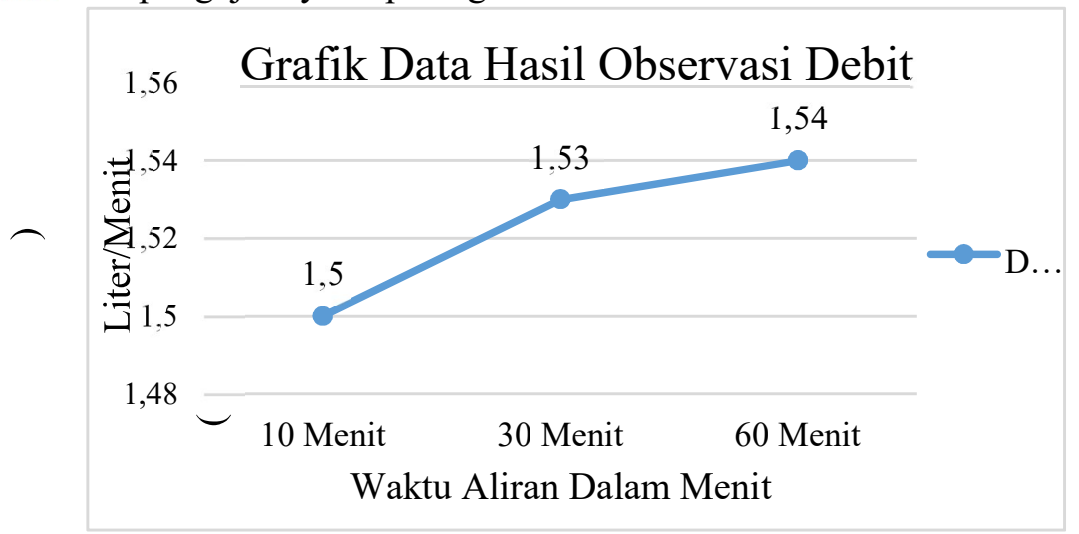

Gambar 6

\subsection{Perhitungan Kehilangan (Head Losses)}

a. Dari persamaan 2.4 perhitungan reynold, maka:

Pada pengujian tahap pertama dengan waktu 10 menit dengan menggunakan persamaan 2.4.

$$
\begin{aligned}
\operatorname{Re} & =\frac{\mathrm{VD} \rho}{\mu} \\
& =\frac{1,5 \times 0,0381 \times 1000}{0,894} \\
\operatorname{Re} & =\frac{57,15}{0,894} \\
\operatorname{Re} & =63,92
\end{aligned}
$$

Maka untuk menghitung head losses pada pengujian tahap pertama menggunakan persamaan 2.5 berikut:

$$
f=\frac{0,316}{\operatorname{Re} 1 / 4} \quad f=\frac{0,316}{63.921 / 4}
$$

$$
\begin{gathered}
=\frac{0,316}{15,98} \\
f=0,02 \mathrm{~m}
\end{gathered}
$$

b. Dari persamaan 2.4 perhitungan reynold, maka:

Pada pengujian tahap kedua dengan waktu 30 menit adalah. 
Vol 4. No. 2, April 2018

ISSN : 2502-0498

$$
\begin{aligned}
\operatorname{Re} & =\frac{\frac{V D}{\mu}}{\mu} \\
& =\frac{1,53 \times 0,0381 \times 1000}{0,894} \\
\operatorname{Re} & =\frac{58,29}{0,894} \\
\operatorname{Re} & =65,20
\end{aligned}
$$

Maka untuk menghitung head losses pada pengujian tahap pertama adalah.

$$
\begin{aligned}
f_{f} & =\frac{0,316}{\operatorname{Re} 1 / 4} \\
& =\frac{0,316}{65,201 / 4} \\
& =\frac{0,316}{16,3} \\
f & =0,01 \mathrm{~m}
\end{aligned}
$$

c. Dari persamaan 2.4 perhitungan reynold, maka:

Pada pengujian tahap ketiga dengan waktu 60 menit adalah.

$$
\begin{aligned}
\operatorname{Re} & =\frac{V D \rho}{\mu} \\
& =\frac{1,54 \times 0,0381 \times 1000}{0,894} \\
\operatorname{Re} & =\frac{58,67}{0,894} \\
\operatorname{Re} & =65,62
\end{aligned}
$$

Maka untuk menghitung head losses pada pengujian tahap pertama menggunakan persamaan berikut:

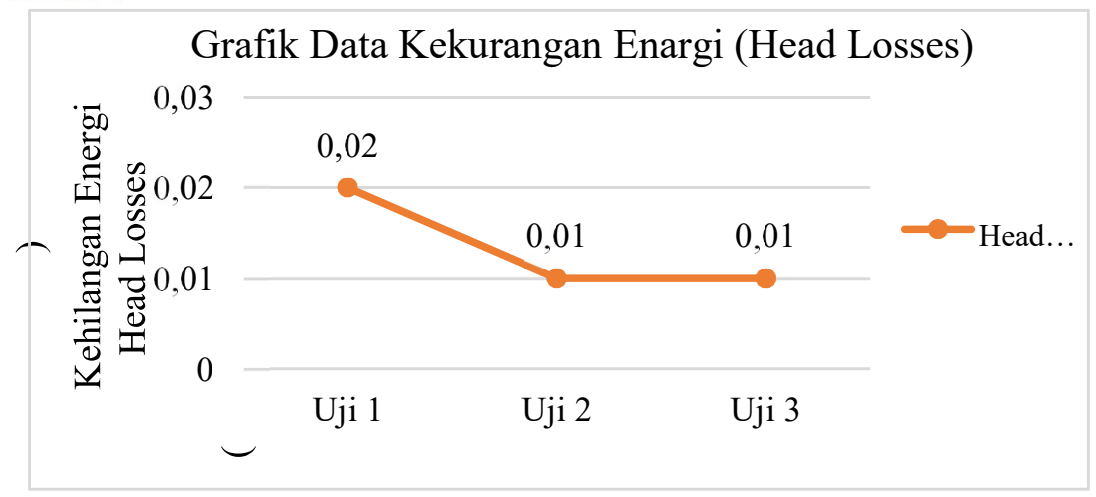

Gambar 7

$$
\begin{aligned}
f_{f} & =\frac{0,316}{\operatorname{Re} 1 / 4} \\
& =\frac{0,316}{65,62 \quad 1 / 4} \\
& =\frac{0,316}{16,40} \\
f & =0,01 \mathrm{~m}
\end{aligned}
$$

\section{Kesimpulan}

Berdasarkan hasil penelitian penulis menyimpulkan hal-hal sebagai berikut:

1. Perancangan kombinasi pompa vakum dengan pompa hidrolik ram menggunakan Software Sketchup. 


\section{Jurnal Mekanova}

Vol 4. No. 2, April 2018

ISSN : 2502-0498

2. Keunggulan dari pembuatan kombinasi pompa vakum dengan pompa hidrolik ram adalah dapat menghisap air dari dataran rendah ke dararan yang lebih tinggi tampa memakai pompa tenaga listrik.

3. Pada pengujian tahap pertama dalam waktu 10 menit volume air yang keluar ratarata dari tiga kali pengujian sebanyak 15 liter, dengan debit 1,5 1/m, dan head losses nya $0,02 \mathrm{~m}$.

4. Pada pengujian tahap kedua dalam waktu 30 menit volume air yang keluar ratarata dari tiga kali pengujian sebanyak 46,1 liter, dengan debit 1,53 1/m, dan head losses nya $0,01 \mathrm{~m}$.

5. Pada pengujian tahap ketiga dalam waktu 60 menit volume air yang keluar ratarata dari tiga kali pengujian sebanyak 92,6 liter, dengan debit 1,54 1/m, dan head losses nya $0,01 \mathrm{~m}$.

\section{DAFTAR PUSTAKA}

[1]. Jimi Indriyan (2007). "Pengaruh Perbedaan Diameter Pipa Hisap Dan Diameter Pipa Pengeluaran Terhadap Kontinuitas Aliran Pada Pompa Vakum". Teknik Mesin Universitas Muhammadiyah Malang

[2]. Kirun (2013). "Jenis-Jenis Pompa". Makassar

[3]. Kuswartomo, Gurawan Djati Wibowo (2012) "Panjang Drive Pipe Terhadap Karakteristik Pompa Hidram" Universitas Negeri Surabaya

[4]. Mietra Anggara. dkk, (2007). "Pengaruh Variasi Panjang Pipa Masuk (Drive Pipe) Dan Beban Katup Buang (Waste Valve) Terhadap Efisiensi Pompa Hidram”. Universitas Widyagama Malang

[5]. Nurbet Wahyudi (2007). "Pengaruh Perbedaan Kapasitas Drum (Tabung) Vakum

Dan Tinggi Pipa Pengeluaran Terhadap Kontinuitas Aliran pada Pompa

Vakum". Teknik Mesin Universitas Muhammadiyah Malang

[6]. Nurul Fahmi, 2015 "Fungsi Dan Peranan Air Bagi Kehidupan". Politeknik Makassar

[7]. Sukma (2016). "Sejarah Pompa Hidrolik Ram". Wonosobo, Jawa Tengah

[8]. www.pompavakumfluida.com, diakses 04 Juli 2018

[9]. www.kelair.bppt.go.id, diakses 04 Juli 2018

[10]. www.khatulistiwa.info, diakses 02 Juli 2018 